\title{
Impactos Econômicos Regionais e Inter-regionais dos Megaeventos Esportivos sediados no Estado do Rio de Janeiro
}

\section{Analysis of Regional and Inter-regional Economic Impacts of the Sporting Mega Events Based in Rio de Janeiro}

\author{
Joilson Assis Cabral* \\ Maria Viviana Freitas Cabral** \\ Thandara Maria Kathleen da Silva***
}

\begin{abstract}
Resumo: Este estudo investigou os impactos dos investimentos dos megaeventos esportivos para a economia do estado do Rio de Janeiro e os possíveis transbordamentos para o restante do Brasil. Para tanto, foi utilizada a matriz de insumo-produto interregional Rio de Janeiro x restante do Brasil para o ano de 2009, atualizada por meio do método RAS. Os principais resultados revelaram que a parcela intra-regional do multiplicador de produção sempre supera a parcela inter-regional, demonstrando que a economia do Rio de Janeiro não gera efeito transbordamento expressivo para a economia do restante do Brasil e vice-versa. Além disso, o PIB do Rio de Janeiro cresceu $13 \%$ em virtude dos investimentos advindos dos megaeventos, enquanto o PIB do restante do Brasil aumentou somente 0,45\%. E, por fim, o crescimento econômico não será sustentado para a economia do Rio de Janeiro, uma vez que os setores favorecidos pelos investimentos dos megaeventos não se apresentaram como chave para a economia fluminense.
\end{abstract}

Palavras-chave: Análise regional. Insumo-produto. Impacto dos megaeventos esportivos.

\begin{abstract}
This paper analyzes the impacts of the investments due to the mega sports events for the economy of the state of Rio de Janeiro and possible spillovers effects in the rest of Brazil. For this, it was used the inter-regional Input-Output Table of state of Rio de Janeiro x remainder of Brazil to the year 2009, updated through the RAS method. The main results revealed that the intra-regional share of the output multiplier always exceeds the interregional share, what demonstrates that the economy of Rio de Janeiro does not generate significant spillover effect to the economy of the rest of Brazil

* Doutorando em Planejamento Energético pelo Instituto Alberto Luiz Coimbra de Pós-Graduação e Pesquisa de Engenharia (COPPE) da Universidade Federal do Rio de Janeiro (UFRJ). Professor do Departamento de Ciências Econômicas da Universidade Federal Rural do Rio de Janeiro (UFRRJ), campus Seropédica. E-mail: cabraljoilson@gmail.com

** Doutora em Economia pela Universidade Federal de Juiz de Fora (UFJF). Professora do Departamento de Ciências Econômicas da Universidade Federal Rural do Rio de Janeiro (UFRRJ), campus Seropédica. E-mail: mvivianafreitas@gmail.com

*** Graduada em Ciências Econômicas pela Universidade Federal Rural do Rio de Janeiro (UFRRJ). Mestranda em Economia Aplicada pela Universidade Federal e Juiz de Fora (UFJF). E-mail: mariathandara92@gmail.com

Os autores agradecem a PROPPG/UFRRJ pelo financiamento deste trabalho no âmbito do Programa de Iniciação Científica da UFRRJ-PROIC. Os autores agradecem ainda os avaliadores anônimos por suas oportunas contribuições.
\end{abstract}


and vice versa. Moreover, the GDP of Rio de Janeiro grew 13\% as result of investments of mega events while the rest of Brazil's GDP had only increased $0.45 \%$. Finally, the economic growth will not be sustained to the economy of the state of Rio de Janeiro, since the sectors favored by investments of the mega events are not presented as the key sectors to Rio de Janeiro's economy.

Keywords: Regional analysis. Input-output. Impacts of the Sporting Mega Events.

JEL Classification: R11; R15.

\section{Introdução}

Com o anúncio, em 2007, da escolha do Brasil como país-sede da Copa das Confederações FIFA 2013 e da Copa do Mundo FIFA 2014 (BRASIL, 2010) e o Rio de Janeiro como cidade-sede do Mundial, abrigando a cerimônia de encerramento do evento e o jogo final (Maracanã), tem-se a retomada dos investimentos no Brasil e no estado fluminense. Afinal, um evento desse porte, de grande visibilidade e inserção internacionais traz uma série de benefícios econômicos e sociais, como a entrada de divisas e consequentes investimentos nacionais e regionais assim como possível aumento do desenvolvimento regional. No que tange ao investimento da Copa do Mundo para o estado do Rio de Janeiro (reforma do Maracanã e construção do corredor viário T5), o montante de recursos é da ordem de $\mathrm{R} \$ 1910$ milhões, equivalente a 12,40\% do investimento total do evento no país, sendo que o financiamento é dividido entre os governos municipal (1,36\%), estadual (0,64\%) e o Banco Nacional do Desenvolvimento (BNDES - 98\%) (BRASIL, 2010).

Em 2009, a cidade do Rio de Janeiro foi escolhida como sede dos Jogos Olímpicos e Paraolímpicos de 2016. Nesse evento, serão investidos 28,8 bilhões de reais, segundo dossiê da candidatura do Rio como sede dos Jogos Olímpicos. Esse total será distribuído da seguinte forma: $\mathrm{R}$ \$,6 bilhões para a estrutura do Comitê Organizador e R\$23,2 bilhões serão destinados à infraestrutura necessária aos Jogos. Um amplo estudo do impacto econômico desse evento foi divulgado pelo Comitê Organizador da candidatura brasileira e os números divulgados ressaltaram os impactos econômicos da realização dos jogos na cidade e no país. Com base nesse estudo, encomendado pelo Ministério do Esporte, estima-se que o impacto econômico dos Jogos Olímpicos e Paraolímpicos sobre o Produto Interno Bruto (PIB) do Brasil será de $\mathrm{R} \$ 22$ bilhões até 2016, enquanto que, no período de 2017 a 2027, atingirá $\mathrm{R} \$ 27$ bilhões. Nesse estudo, foram identificados, ainda, os setores da economia que mais poderão se beneficiar com a realização do megaevento: construção civil (10,5\%), serviços imobiliários e aluguel (6,3\%), serviços prestados a empresas (5,7\%), petróleo e gás (5,1\%), serviços de informação (5\%) e transporte, armazenagem e correio (4,8\%) (BRASIL, 2010). 
Ademais, a literatura de economia dos esportes afirma que diversos outros setores produtivos, além dos supracitados, terão impactos econômicos e sociais positivos advindos dos grandes eventos esportivos. Dentre eles, podemos citar: ampliação dos setores de serviços e hotelaria, fluxo adicional de turistas no evento e pós-evento, exposição internacional do país e atração de investimento externo (BETARELLI JUNIOR et al., 2010).

Desde que o Brasil foi anunciado como sede da Copa do Mundo de 2014, tendo o Rio de Janeiro (Maracanã) como cidade escolhida para a cerimônia de encerramento do evento e a capital fluminense sendo eleita como cidade-sede dos Jogos Olímpicos de 2016, muito se especula a respeito dos impactos que os eventos vão gerar nas economias fluminense e brasileira, pois os setores da economia são interligados por meio de uma cadeia produtiva, logo um investimento nas indústrias e serviços do Rio de Janeiro possui o impacto de gerar crescimento/ desenvolvimento da economia do próprio estado e no restante do Brasil.

Nesse sentido, Hirschman (1958) classifica as cadeias produtivas de duas formas: retrospectivas (linkages "para trás") e prospectivas (linkages "para frente"). Segundo o autor, cadeias retrospectivas induziriam novas atividades devido à utilização de insumos indispensáveis àquela atividade enquanto cadeias prospectivas tentariam utilizar a produção como insumo de algumas novas atividades. No caso de firmas, as empresas que proporcionariam maior crescimento seriam aquelas que possuem maiores números de linkages dentro da região a ser desenvolvida. Hirschman (1958) conclui que um bom instrumento para analisar estes linkages é a matriz de insumo-produto, pois nela é possível encontrar a proporção da produção destinada ao consumo intermediário e a proporção que é destinada à demanda final. Para o autor, linkages "para trás" expressam as externalidades decorrentes da implantação de indústrias que, ao aumentarem a demanda de insumos no setor a montante, viabilizariam suas escalas mínimas de produção na região. Os linkages "para frente", por sua vez, resultariam da oferta de insumos que tornaria viáveis os setores que se posicionassem a jusante. Hirschman (1958) também notou os efeitos dos multiplicadores dos setores-chave sobre o produto, a renda e o emprego, além desses setores induzirem o surgimento de novas atividades.

Nesse mesmo sentido, Perroux (1955) enfatiza que o crescimento regional se dá através da implantação de uma indústria-chave, isto é, uma indústria que possui a propriedade de aumentar as vendas (e compras) de serviço de outra indústria ou de várias outras indústrias (movidas) ao aumentar suas vendas (e suas compras) de serviços produtivos. Posto de outra forma, empresa-chave é aquela que possui muitos encadeamentos (linkages) "para frente" e "para trás".

Tendo em vista o panorama de retomada de investimentos por ocasião dos megaeventos esportivos a serem realizados no país, faz-se necessário o entendimento do comportamento dos fluxos de recursos sobre a cadeia produtiva da 
economia fluminense para a dinâmica de desenvolvimento do estado do Rio de Janeiro e para o restante do Brasil. Nesse contexto, torna-se necessária a mensuração da efetividade dos impactos decorrentes dos investimentos vindouros, isto é, analisar se esses investimentos surtirão os efeitos esperados pelo Ministério do Esporte sobre as economias fluminense e do restante do Brasil. Diante do discorrido, o presente trabalho possui como objetivo central mensurar os impactos regionais oriundos dos investimentos da Copa do Mundo de 2014 e dos Jogos Olímpicos de 2016 para a economia do estado do Rio de Janeiro e, ainda, serão analisados os possíveis transbordamentos desses investimentos para outras regiões do Brasil. Para tal, foi utilizada a matriz de insumo-produto (MIP) inter-regional Rio de Janeiro x restante do Brasil do ano de 2004, disposta em 20 setores produtivos para cada região como base para a atualização da MIP de 2004 para o ano de 2009, por meio do método RAS, de modo a implementar o modelo inter-regional de insumo-produto e seus indicadores clássicos.

As evidências obtidas neste trabalho mostraram que os setores-chave da economia do Rio de Janeiro são Mineração e Energia Elétrica, afinal, trata-se do maior estado prospector de petróleo no Brasil e com considerável parque gerador elétrico. Além disso, a parcela intra-regional do multiplicador de produção sempre supera a parcela inter-regional, demonstrando que variações na demanda final do Rio de Janeiro não geram efeito transbordamento expressivo sobre a economia do restante do Brasil e vice-versa. Em relação ao PIB de 2009, o PIB do Rio de Janeiro cresceu $13 \%$ em virtude dos investimentos advindos dos megaeventos enquanto o PIB do restante do Brasil aumentou somente $0,45 \%$. No entanto, esse crescimento não será sustentado, uma vez que os setores de Transporte, Construção e Material Elétrico e Eletrônicos do Rio de Janeiro, que obtiveram maior impacto sobre o valor adicionado, não possuem o poder de dinamizar a economia fluminense, pois não possuem encadeamentos fortes intra e intersetoriais.

Além desta seção introdutória, o presente trabalho está estruturado como segue. A segunda seção traz a revisão de literatura acerca dos principais impactos econômico-sociais dos megaeventos esportivos. A terceira seção aborda a metodologia implementada bem como a descrição dos dados utilizados. Já na quarta seção, são discutidos os resultados e, por fim, as considerações finais do estudo são empreendidas na quinta seção.

\section{Revisão de Literatura}

Esta seção possui como objetivo fazer um levantamento bibliográfico, tanto na literatura nacional quanto internacional dos trabalhos que visam examinar os impactos regionais oriundos de megaeventos esportivos. Cabe salientar que essa revisão será breve e, dessa forma, não vai exaurir o tema proposto, mas tão so- 
mente verificar possíveis lacunas a serem preenchidas por este trabalho, além de ajudar na interpretação dos resultados obtidos pelo mesmo.

Tavares (2004) buscou identificar os vencedores e perdedores dos Jogos Olímpicos de 2016 considerando os interesses envolvidos e os resultados concretos de sua realização. Para alcançar seu objetivo, o autor realizou uma revisão de literatura das edições anteriores dos jogos e concluiu que, por meio da análise dos interesses relacionados à realização dos jogos, é possível identificar seus vencedores. Para o autor, os membros do Comitê Olímpico Internacional (COI), os governos, os políticos da administração municipal, as empresas do setor de construção, as classes médias e superiores e também os trabalhadores estão incluídos no grupo dos que se beneficiariam com os jogos. Por outro lado, através dos efeitos gerados, foi possível identificar também os potenciais perdedores. Nesse grupo encontram-se aqueles que estão em posições vulneráveis, como os grupos de menor poder aquisitivo da população. Portanto, de acordo com o autor, uma candidatura olímpica deve avaliar o risco dos efeitos negativos possíveis, uma vez que a realização dos Jogos pode apresentar um saldo sócio-político-econômico inferior ao esperado e mesmo ampliar a polarização e a desigualdade social.

Já Matheson (2006) procurou mensurar os efeitos econômicos dos megaeventos esportivos. O trabalho mostra que as previsões realizadas ex-ante tendem a superestimar os benefícios gerados por esses eventos ao passo que os estudos ex-post mostram os verdadeiros impactos provocados. O autor utilizou como metodologia uma pesquisa qualitativa a respeito do tema. A análise mostrou que os estudos realizados ex-ante possuem problemas em relação aos multiplicadores utilizados e, ainda, possuem deficiências teóricas em relação aos efeitos substituição, crowding out e transbordamentos. Em virtude desses problemas, o autor afirma que devem ser realizados estudos ex-post nas cidades que já sediaram os eventos esportivos. Esses estudos teriam como objetivo verificar se os impactos previstos ocorreram de fato. $\mathrm{O}$ trabalho confirmou as críticas citadas anteriormente, ou seja, o autor evidenciou que os estudos ex-ante, frequentemente, superestimam os benefícios gerados pelos megaeventos. Por fim, o autor faz sugestões a respeito de políticas que podem ser adotadas pelas cidades-sede de forma a maximizar os seus ganhos decorrentes de um evento, como melhorias na infraestrutura, além da promoção de uma série de eventos pequenos no lugar de poucos megaeventos, onde aqueles tendem a gerar maiores benefícios líquidos.

Haddad et al. (2008) objetivaram estimar os impactos dos gastos públicos e privados decorrentes da realização dos Jogos Pan-Americanos de 2007 na cidade do Rio de Janeiro considerando os efeitos multiplicadores desses gastos sobre a produção total e setorial (42 setores), o valor adicionado, a massa salarial, o emprego e a arrecadação de impostos indiretos para o Município do Rio de Janeiro e sua região metropolitana, o restante do estado e o restante do país. A fim de 
alcançar o objetivo proposto, os autores utilizaram a metodologia inter-regional de insumo-produto e os multiplicadores clássicos de produção, emprego e renda. Os autores concluíram que quanto maior o grau de interdependência produtiva e quanto menor o grau de vazamentos nos fluxos de produção e de renda de um nível espacial para outras regiões, maiores serão os valores dos efeitos multiplicadores. De forma geral, os impactos dos gastos geraram benefícios no emprego, na renda e nos tributos para todas as regiões analisadas. Entretanto, os maiores impactos ocorreram para o "resto do país", o que pode ser devido ao expressivo grau de especialização produtiva que ocorre na economia fluminense e sua consequente dependência da importação de bens e serviços em grande escala (vazamentos nos fluxos de produção e renda).

Romero e Ribeiro (2009), por sua vez, buscaram analisar os impactos oriundos da realização de megaeventos, destacando, principalmente, os impactos relacionados ao transporte e à mobilidade urbana, considerando que esses constituem um dos principais problemas encontrados no Brasil atual, em especial na cidade do Rio de Janeiro, que se prepara para sediar dois megaeventos esportivos nos próximos anos, a Copa do Mundo de Futebol 2014 e as Olimpíadas 2016. A fim de alcançarem o objetivo proposto, os autores utilizaram uma metodologia baseada em uma revisão bibliográfica, clipping e análise histórica de casos semelhantes, como as Olimpíadas de Barcelona (1992) e de Pequim (2008) e a Copa do Mundo de Futebol realizada na Alemanha em 2006. Em relação ao setor de transporte, é destacada a importância de as agências públicas explorarem as informações de que dispõem a fim de preverem os impactos provocados por um megaevento. Com isso, essas agências podem planejar e aplicar técnicas que evitem efeitos contrários àqueles gerados por um evento como congestionamentos, acidentes e poluição. Entre as técnicas, merece destaque o gerenciamento de tráfego e demanda e o incentivo ao uso da bicicleta. Por fim, os autores concluíram que os impactos decorrentes de um megaevento podem ser positivos ou negativos. Sob esse ângulo, as informações e diretrizes políticas são aspectos de grande importância para maximizar seus benefícios. São ressaltadas também as diferenças entre as cidades-sede, sendo que aquelas que se encontram em processo de desenvolvimento devem se valer dos megaeventos para realizar projetos estruturais e efetivos.

Na mesma linha de análise de Romero e Ribeiro (2009), Proni (2009) buscou examinar os possíveis impactos econômicos da realização das Olimpíadas de 2016 na cidade do Rio de Janeiro por meio da análise das experiências anteriores consideradas vitoriosas: Barcelona (1992), Sydney (2000) e Pequim (2008). O autor concluiu que os Jogos podem impulsionar os investimentos em infraestrutura, além de serem um elemento dinamizador nas áreas de turismo e geração de empregos. Contudo, as projeções tendem a superestimar os verdadeiros impactos que venham a ser obtidos, conforme alertado por Matheson (2006). Além disso, o 
autor enfatiza a importância da participação do Estado nas fases de planejamento e organização dos Jogos. Por fim, de acordo com o autor, o principal legado dos Jogos de 2016 não será a nível econômico, mas sim em relação à revitalização urbana, ainda que os impactos positivos dos Jogos distribuir-se-ão de maneira heterogênea entre a população.

Lo Bianco (2010) analisou como as políticas públicas decorrentes da realização dos Jogos Olímpicos de 2016 poderão proporcionar legados à cidade do Rio de Janeiro, principalmente no que tange ao esporte e à educação. $\mathrm{O}$ autor também utilizou uma perspectiva comparada como metodologia para alcançar o objetivo proposto, ou seja, uma análise de experiências anteriores bem sucedidas - Barcelona e Londres - em relação aos erros e acertos das políticas adotadas como forma de promoverem maior inclusão social. Dessa forma, verificam-se os possíveis desafios que serão enfrentados pelo Rio de Janeiro considerando as suas especificidades históricas e políticas. $\mathrm{O}$ autor concluiu que o acordado na candidatura pode proporcionar um legado pós-evento, desde que o projeto esteja integrado ao planejamento de longo prazo da cidade, além de demonstrar a importância da participação da sociedade no que tange a identificar as demandas sociais. Ademais, as experiências das outras cidades citadas fornecem parâmetros para a implementação do plano olímpico no Rio de Janeiro. Sob esse ponto de vista, o principal desafio da cidade seria a coordenação entre o mercado e o Estado, como ocorreu nas cidades mencionadas, de forma a evitar o risco de se privilegiar o interesse privado em detrimento do público. O Governo seria, portanto, importante instrumento para a promoção de um legado nas áreas social e urbana.

Já Silva et al. (2011) avaliaram as expectativas da mídia relativas ao futuro legado das Olimpíadas de 2016 para a cidade do Rio de Janeiro considerando o enfoque das racionalidades instrumental e substantiva. Cabe explicitar que a racionalidade instrumental baseia-se na lógica capitalista ligada a relação custo/benefício, enquanto a racionalidade substantiva é pautada nos valores humanos. Para alcançarem o objetivo proposto, foi utilizada como metodologia a catalogação das notícias veiculadas sobre o tema a partir da consulta de 360 edições de cinco importantes jornais que circulam no estado do Rio de Janeiro, considerando as edições impressas e online. Depois de analisada, cada notícia foi enquadrada em uma das 17 categorias construídas pelos autores. ${ }^{1}$ As categorias que apresentaram maior percentual de notícias veiculadas na mídia foram transporte (25\%), empregos (15\%), meio ambiente (8\%) e vias públicas (8\%). O estudo mostrou também que categorias vinculadas à perspectiva substantiva como saúde e transparência pública apresentaram baixo percentual de notícias veiculadas (3\%). Diante dessa

1 São elas: Transporte, Empregos, Meio ambiente, Vias públicas, Turismo, Segurança pública, Sinalização da cidade, Negócios, Saúde, Transparência política, Saneamento público, Reassentamento de famílias, Internet banda larga, Segurança privada, Construção Civil, Reciclagem do lixo e Restauração da cidade. 
categorização, os autores concluíram que, como ocorreu em outros megaeventos, a perspectiva instrumental se sobrepôs à substantiva no que tange às expectativas da mídia sobre o legado dos jogos para a cidade.

Valendo-se também de uma pesquisa bibliográfica básica (periódicos, livros e reportagens quaisquer a respeito do tema), Santos Neto et al. (2011) buscaram analisar a possibilidade dos megaeventos esportivos promoverem o desenvolvimento local. Dessa forma, os autores fazem uma fundamentação teórica pautada no conceito e características do desenvolvimento local, além de apresentarem uma discussão a respeito dos impactos gerados nas cidades que sediaram as edições anteriores dos Jogos. Os autores concluíram que os megaeventos constituem-se em agente facilitador do desenvolvimento local, considerando que há convergência dos interesses públicos e privados para a sua ocorrência. Entretanto, deve-se atentar para o fato de que apenas uma parcela da população se beneficia com a realização do evento.

Bonassa e Faria (2011) analisaram os efeitos relativos à realização dos Jogos Olímpicos de 2016 na cidade do Rio de Janeiro mostrando a importância de um evento como este, assim como seus impactos positivos ou negativos. Para alcançar o objetivo desejado, os autores analisam os aspectos inerentes às Olimpíadas bem como fazem um retrospecto de algumas edições anteriores dos Jogos. O trabalho mostrou que muitos países emergentes utilizam-se da organização de um megaevento como forma de acelerar seu desenvolvimento econômico e de melhorar sua imagem internacionalmente. Além disso, melhorias nas áreas de infraestrutura, turismo, emprego e comércio, além do aumento da autoestima da população do país são outros benefícios gerados por sediar um megaevento. Cabe ressaltar que, devido ao elevado volume de investimentos, os Jogos criam oportunidades para novos empreendedores, porém, os autores alertam para a possibilidade de déficits públicos e aumento do custo de vida.

De maneira empírica, Domingues et al. (2011) buscaram estimar alguns dos impactos da Copa do Mundo de Futebol de 2014, a nível nacional e estadual, por meio dos investimentos previstos. Para alcançar tal objetivo, os autores utilizaram o modelo de equilíbrio geral computável IMAGEM-B. O modelo trabalha com os 27 estados, produzindo resultados para os 5507 municípios. Além disso, a base de dados corresponde à estrutura da produção brasileira do ano de 2003. Dessa forma, foram realizadas sete simulações divididas de acordo com as fontes de financiamento para os estádios e infraestrutura urbana: seis delas correspondem à fase de construção dos investimentos previstos, enquanto a última visa avaliar os ganhos de produtividade decorrentes da operação das obras de infraestrutura urbana. Os resultados mostraram que, a nível nacional, os investimentos da Copa do Mundo de Futebol de 2014 provocarão uma elevação de 0,7\% no PIB e de 0,5\% no emprego, enquanto a nível estadual haverá impacto positivo sobre o nível de 
atividade, destacando-se os estados de Amazonas, Rio Grande do Norte, Ceará e Pernambuco. O estudo também mostrou que os impactos concentrar-se-ão nos estados que possuem estrutura produtiva complexa e alta relação de interdependência com os demais estados. Em relação às cidades-sede, o estudo apontou uma melhoria na infraestrutura urbana. Por fim, o estudo sinalizou a redução dos impactos econômicos em decorrência do financiamento público para a construção dos estádios, uma vez que estes representam o aumento da dívida pública ou a redução dos gastos dos governos envolvidos (federal, estadual e municipal).

Porto et al. (2013) analisaram os futuros impactos da realização da Copa do Mundo de 2014 para o Brasil, destacando-se, principalmente, as regiões que sediarão os jogos. Para isso, utilizam o método indutivo analisando a relação entre os impactos e seus respectivos efeitos sobre a população atingida. As áreas consideradas foram a social, econômica e ambiental. No campo social, os impactos provocados são referentes à moradia. Nesse aspecto, problemas como a remoção de famílias e a especulação imobiliária nas áreas próximas aos estádios mereceram destaque. Além disso, é frisado que a população menos favorecida será a mais prejudicada. Já em relação à esfera ambiental, é demonstrada a importância de se realizar estudos antes do início das obras, a fim de minimizar os possíveis impactos negativos. No que tange aos aspectos econômicos, convém lembrar que o evento trará benefícios ao país, mas, por outro lado, ocasionará prováveis impactos negativos, como a possibilidade de os estádios se tornarem "elefantes brancos", visto que a maior parte dos recursos provém do financiamento público. Deve-se somar a isso o fato de apenas uma reduzida parcela da população ser beneficiada com a organização do evento. Por fim, o estudo criticou o grande dispêndio monetário com a Copa, uma vez que estes recursos poderiam ser alocados em áreas prioritárias, como saúde e educação.

Baseados no método de dados em painel, Souza et al. (2012) buscaram analisar os impactos da Copa do Mundo, no curto prazo, oriundos da expansão dos setores da economia brasileira sobre o PIB estadual, considerando as 27 unidades da federação no período anual de 1992 a 2008. Os setores considerados foram os de Construção Civil, Turismo, Comércio, Imóveis e Transporte e Comunicação, pois acredita-se que esses serão os setores mais beneficiados com a realização da Copa de 2014. Os resultados mostraram que as atividades que geram maiores impactos sobre o PIB estadual são as relacionadas aos setores de imóveis e comércio, apresentando elasticidades iguais a 0,399 e 0,263, respectivamente. Essas atividades serão financiadas, principalmente, pelo setor privado. Conhecendo os coeficientes de elasticidade em cada setor é possível prever cenários de investimentos para a Copa em termos setoriais, ou seja, a partir das estimativas do estudo, os setores que deveriam receber maiores incentivos, em ordem decrescente, são os de Imóveis, Comércio, Transporte e Comunicação, Turismo e Construção Civil, por gerarem 
considerável impacto sobre o PIB regional. Além disso, a análise das estimativas dos coeficientes confirma o fato de o setor de serviços se sobrepor sobre os demais setores da economia.

Proni e Silva (2012) discutem a respeito dos efeitos esperados da Copa do Mundo de 2014 no Brasil, focando, principalmente, no ponto da superestimação das projeções dos impactos econômicos divulgados pelo Governo Federal, como apontado por Matheson (2006) e Proni (2009). Os autores basearam-se em uma revisão bibliográfica, análise documental, acesso a fontes oficiais de informação e, ainda, acesso a sites de jornais e revistas para alcançar o objetivo proposto. A análise dos impactos econômicos nas duas últimas nações que sediaram a Copa, Alemanha (2006) e África do Sul (2010), mostrou que os estudos ex-ante são frequentemente superestimados, visto que se utilizam de muitas simplificações, além de não considerarem algumas premissas econômicas. Dessa forma, os estudos dos impactos otimistas servem apenas para justificar os elevados gastos públicos, afinal, os estudos ex-post apontam efeitos diferentes. O trabalho alerta para a ocorrência desse fato em relação à Copa de 2014. Os autores frisam, da mesma forma que Lo Bianco (2010), a importância da participação do Estado na organização do evento, considerando que os benefícios e prejuízos não se distribuem de forma igualitária entre as diferentes partes envolvidas. Sob essa perspectiva, os efeitos positivos tendem a se concentrar nas cidades-sede, ainda que de maneira distinta. Convém destacar que em países subdesenvolvidos como o Brasil, a realização de um megaevento como a Copa provoca um trade-off para o Governo, pois, por um lado, o evento serve para impulsionar o volume de investimentos em infraestrutura ao passo que, por outro, necessita-se do adiamento de investimento em outras áreas.

Ganguly (2012) analisou as oportunidades de investimentos que o Brasil pode aproveitar por ser sede de dois megaeventos, além de avaliar os possíveis impactos econômicos. O estudo é baseado numa breve análise do Brasil atual e em uma discussão das experiências olímpicas anteriores. Em relação à última, exemplos como Barcelona e Los Angeles são apontados como sucesso, ao passo que os Jogos na Grécia foram considerados um fracasso. Convém ressaltar que, segundo o autor, embora haja altos custos provenientes da realização desses eventos, os benefícios gerados podem ser ainda maiores, a exemplo, o prestígio internacional, o melhoramento na infraestrutura do país, além de impulsionar vários setores, como o turismo. Destaca-se, ainda, o fato de o Brasil sediar esses dois eventos, consecutivamente, proporcionar ao país custos menores do que sediá-los separadamente, visto que os eventos possuem projetos em comum, o que pode gerar ganhos de escala. O autor concluiu que o Brasil possui condições de realizar os eventos mencionados com êxito, desde que sejam tomadas algumas precauções em relação aos custos e benefícios, pois a análise de edições passadas demonstrou que há o 
risco de se superestimar os ganhos e/ou extrapolar os custos. Além disso, é destacada a importância da participação do Estado nos projetos de infraestrutura, mas seria recomendável uma parceria público-privada a fim de dividir os riscos e os custos.

Costa (2013) buscou avaliar a viabilidade de sediar megaeventos como as Olimpíadas mostrando os impactos positivos e negativos nos âmbitos social e econômico. Para isso, a autora faz uma revisão da bibliografia internacional sobre o tema e das experiências disponíveis, além de discutir algumas das transformações que estão ocorrendo na cidade do Rio de Janeiro, sede dos próximos Jogos Olímpicos. Do lado econômico, a análise da literatura aponta para a existência de benefícios individualizados diretos, como o aumento do número de empregos, ou indiretos, como a melhora da imagem do país a nível internacional. Além disso, os benefícios indiretos podem ser maiores que os diretos, apesar de mais complexos de serem mensurados. Entretanto, as experiências passadas mostram que sediar megaeventos pode não resultar em impactos positivos, mas, pelo contrário, causar sérios impactos negativos, como custos maiores do que os previstos e endividamento público. No que tange aos impactos na esfera social, sediar megaeventos traria apenas ganhos a uma parcela restrita da população, especialmente às classes de empresários e políticos, ou seja, a classe de renda mais alta, já que a população de classe de renda mais baixa raramente seria beneficiada. No caso do Rio de Janeiro, a autora apontou, ainda, alguns dos problemas que já aparecem, como o aumento dos gastos, falta de transparência na tomada de decisões, despejo de moradores de comunidades carentes, entre outros.

Por meio dessa breve revisão bibliográfica, pôde-se perceber que os impactos dos megaeventos esportivos têm sido abordados pela literatura em estudos utilizando como metodologia, principalmente, análise bibliográfica comparativa, ou seja, comparando as experiências anteriores com a nacional, além de alguns testes empíricos como modelo econométrico, insumo-produto e equilíbrio geral computável. Por meio dessa investigação, verificou-se que os trabalhos empíricos procuraram tratar e examinar os mais variados impactos oriundos dos megaeventos, quais sejam, i) impactos econômicos; ii) impactos sociais; iii) impactos ambientais e iv) setores e classes ganhadores e perdedores. Cabe salientar que esse levantamento bibliográfico preliminar não encontrou estudos que utilizam a metodologia de insumo-produto, proposta pelo presente trabalho, para verificar os possíveis impactos dos megaeventos, Copa do Mundo de 2014 e Jogo Olímpicos de 2016. Diante disso, este trabalho contribui para a literatura vigente em Economia Regional ao propor uma análise dos possíveis impactos intra e inter-regionais dos megaeventos esportivos por meio da análise inter-regional de insumo-produto. 


\section{Aspectos Metodológicos e Base de Dados}

Esta seção visa descrever a metodologia que será utilizada com o intuito de alcançar os objetivos propostos anteriormente e gerar informações que facilitem a interpretação dos resultados, além de informar os dados utilizados neste trabalho.

\subsection{Modelo Inter-regional de Insumo-Produto}

A estrutura analítica de insumo-produto, desenvolvida por Leontief (1941), fornece a descrição completa das interdependências ou interações (sobre as óticas de compra e venda) dos setores produtivos em determinado tempo e localidade (nação, região, estado) (MILLER; BLAIR, 2009). A análise de insumo-produto possui aderência para estudar as interdependências ou interações entre setores da economia de uma região ou país (HADDAD et al. 2008). O grau de interdependência pode ser avaliado por meio de medidas conhecidas como coeficientes de requerimento intersetorial. Esses coeficientes permitem avaliar, por exemplo, os impactos ocorridos no valor bruto da produção de uma região oriundos de variações na demanda final dessa região, assim como de outras regiões (modelo inter-regional).

O modelo de insumo-produto parte da hipótese de equilíbrio, na qual a quantidade demandada é idêntica à quantidade produzida de bens e serviços. Ademais, esse modelo detém limitações, como: (i) relação fixa entre a produção de cada setor e os insumos utilizados (coeficiente tecnológico constante), (ii) retornos constantes de escala, (iii) demanda final definida exogenamente e (iv) preços constantes (BETARELLI JUNIOR, 2007; CABRAL; PEROBELLI, 2012).

Segundo Miller e Blair (2009), a matriz inter-regional de insumo-produto descreve fluxos monetários de bens e serviços entre diferentes regiões. Neste trabalho, a matriz inter-regional de insumo-produto utilizada é constituída de duas regiões (Rio de Janeiro e restante do Brasil) e 20 setores produtivos. Os fluxos intersetoriais de bens e serviços de uma economia com duas regiões e $n$ setores, determinados por fatores tecnológicos e econômicos, podem ser representados da seguinte forma (MILLER; BLAIR, 2009):

$$
\begin{gathered}
z_{11}^{R J R J}+\cdots+z_{120}^{R J R}+z_{11}^{R J R B}+\cdots+z_{120}^{R J R B}+y_{1}^{R J}=X_{1}^{R J} \\
\vdots \\
z_{201}^{R J R J}+\cdots+z_{2020}^{R J R J}+z_{201}^{R J R B}+\cdots+z_{2020}^{R J R B}+y_{20}^{R J}=X_{20}^{R J} \\
z_{11}^{R B R J}+\cdots+z_{120}^{R B R J}+z_{11}^{R B R B}+\cdots+z_{120}^{R B R}+y_{1}^{R B}=X_{1}^{R B} \\
\vdots \\
z_{201}^{R B R J}+\cdots+z_{2020}^{R B R J}+z_{201}^{R B R B}+\cdots+z_{2020}^{R B R B}+y_{20}^{R B}=X_{20}^{R B}
\end{gathered}
$$


Onde: o vetor $Z_{n n}^{R J R J}$ representa as vendas dos $n$ setores $^{2}$ da região do Rio de Janeiro para os $n$ setores da mesma região (vendas intra-regionais), enquanto que o vetor $Z_{n n}^{R J R B}$ representa as vendas dos $n$ setores do Rio de Janeiro para os $n$ setores do restante do Brasil (vendas inter-regionais). O vetor $y_{n}^{R J}$ representa a demanda final dos n setores do Rio de Janeiro e $X_{n}^{R J}$ denota o valor bruto da produção dos $n$ setores do Rio de Janeiro.

De maneira análoga ao descrito anteriormente, no vetor $Z_{n n}^{R B R J}$ são identificados os valores monetários das vendas inter-regionais do restante do Brasil para do Rio de Janeiro e no vetor $Z_{n n}^{R B R B}$ aparecem as vendas intra-regionais do restante do Brasil. O vetor $y_{n}^{R B}$ representa a demanda final dos $n$ setores do restante do Brasil e $X_{n}^{R B}$ denota o valor bruto da produção dos $n$ setores do restante do Brasil.

Escrevendo a equação (1) em notação matricial temos:

$$
\mathrm{Zi}_{2 \mathrm{n}}+\mathrm{Y}=\mathrm{X}
$$

Nessa forma, $Z$ é uma matriz $2 n \times 2 n$, que representa as relações inter-setoriais, $\mathrm{i}_{2 n}$ é um vetor unitário de ordem $2 n \times 1$, Y é um vetor 2 nx1 onde são denotados a demanda final de ambas as regiões e, por fim, $X$ é um vetor $2 n \times 1$, onde os elementos representam o Valor Bruto da Produção dos setores do Rio de Janeiro e do restante do Brasil.

A equação (2) pode ser representada por meio da matriz de coeficientes técnicos (A). Cabe salientar que a matriz A também é chamada de matriz de coeficientes diretos. Utilizando a matriz A na equação anterior temos:

$$
\mathrm{A}=\mathrm{Z}(\hat{X})^{-1}
$$

Em que $\hat{X}$ é a matriz diagonal de $X$ (valor bruto da produção) e cada elemento da matriz de coeficientes diretos (A) é definido da seguinte forma:

$$
\mathrm{a}_{\mathrm{ij}}=\mathrm{z}_{\mathrm{ij}} / \mathrm{x}_{\mathrm{j}}
$$

Onde $\mathrm{a}_{\mathrm{ij}}$ é chamado de razão de insumo-produto, coeficiente técnico ou coeficiente de requerimento direto e fornece informações sobre os efeitos diretos de uma variação da demanda final. Por meio da equação (4), ainda, é possível verificar que a razão de coeficientes técnicos representa a relação fixa entre os insumos utilizados na produção e o total produzido por cada setor.

A matriz A em um modelo de insumo produto inter-regional é dividida em quatro sub matrizes, como segue abaixo.

$2 \quad$ Vale ressaltar que neste trabalho $n$ varia de 1 a 20 , visto que a matriz inter-regional utilizada possui 20 setores produtivos. 


$$
A=\left[\begin{array}{ll}
A^{R J R J} & A^{R J R B} \\
A^{R B R J} & A^{R B R B}
\end{array}\right]
$$

Na diagonal principal da matriz A são explicitados os coeficientes técnicos intra-regionais $\left(\mathrm{A}^{\mathrm{RJRJ}}, \mathrm{A}^{\mathrm{RBRB}}\right)$, enquanto que a diagonal secundária denota os coeficientes diretos inter-regionais ( $\mathrm{A}^{\mathrm{RBRJ}}, \mathrm{A}^{\mathrm{RJRB}}$ ). Substituindo a equação (3) na equação (2), tem-se:

$$
A X+Y=X
$$

Colocando a equação anterior em função de $Y$ (demanda final), chega-se a:

$$
X=(I-A)^{-1} Y
$$

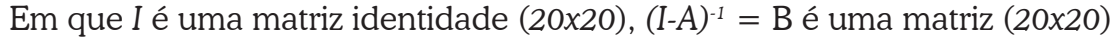
conhecida como matriz inversa de Leontief ou matriz de coeficientes diretos e indiretos.

Diante do apresentado, a equação chave do Modelo de Insumo-Produto inter-regional é, portanto, dada por:

$$
X=B Y
$$

\subsubsection{Atualizando e projetando os coeficientes: a abordagem RAS}

Conforme destacado por Miller e Blair (2009), a parte mais importante de uma matriz de insumo-produto são os coeficientes técnicos, pelo fato de demonstrarem as relações entre os setores da economia e, com o passar do tempo, diversos fatores alteram esses coeficientes técnicos. ${ }^{3}$ Porém, como salientado por Souza e Perobelli (2009), a construção de uma matriz por meio de uma pesquisa econômica despende tempo e recursos financeiros, tanto em nível nacional como regional, dificultando, por conseguinte, a constante divulgação das matrizes de insumo-produto.

Para resolver esse impasse, o presente trabalho realiza a atualização da matriz de insumo-produto inter-regional do Rio de Janeiro $\mathrm{x}$ restante do Brasil do ano de 2004 para o ano de 2009, visando identificar os impactos econômicos dos grandes eventos esportivos a serem sediados no estado do Rio de Janeiro. Cabe destacar que, de acordo com a literatura macroeconômica, mudanças na estrutu-

3 Podem ser citados: mudanças tecnológicas, grande crescimento na demanda de produtos de um setor específico, invenção de novos produtos, mudanças nos preços relativos e mudanças na produção doméstica para insumos importados e de produtos importados para insumos internos. 
ra produtiva ocorrem somente no longo prazo, o que viabiliza a análise supracitada, uma vez que o intervalo de tempo será de apenas cinco anos a partir da matriz atualizada (CABRAL; PEROBELLI, 2012).

A primeira apresentação sistemática de mudanças tecnológicas no contexto de tabelas de insumo-produto, usando uma abordagem formal, é devida a Stone (1963), no que ele chamou de método RAS. Pelo fato de o método RAS requerer somente informações recentes sobre os totais das linhas/colunas de determinada matriz, esse é um dos procedimentos mais utilizados para atualização de matrizes. Lahr e De Mesnard (2004) apontam duas vantagens do RAS em relação a outros métodos de atualização de MIPs: i) trata-se de um algoritmo de fácil implementação, ii) a aplicação do método demanda poucos dados, o que torna menos custoso em termos financeiros.

O método RAS consiste em um mecanismo iterativo, que busca ajustar os valores das linhas e colunas da matriz de coeficientes técnicos com seus totais, considerando a proporcionalidade dos valores totais. Esse método calcula um novo conjunto de valores para as células de uma matriz, a partir de uma estrutura já existente, fazendo com que a soma das linhas e das colunas fique consistente com o total esperado 4 (PALERMO et al., 2010).

Assim, a técnica RAS possibilita a estimação de $n^{2}$ coeficientes por meio de $3 n$ informações do ano alvo, ou seja, conhecidos os vetores do valor bruto da produção e do consumo intermediário (pela ótica das vendas e pela ótica das compras) de 2009, é possível estimar os 400 coeficientes diretos para o Rio de Janeiro e o restante do Brasil para o referido ano. De acordo com Teixeira e Silva (1978), a abordagem RAS consiste, em suma, em uma tentativa de atualizar a matriz de insumo-produto, levando em consideração dois efeitos simultâneos: i) variações relativas nas proporções de insumos requeridos em certas indústrias (mudanças no processo produtivo) e ii) mudanças na produtividade, isto é, deslocamento das tendências upward e downward, no grau de fabricação de certas indústrias.

O primeiro efeito é chamado "substituição" e o segundo "fabricação" ou "produtividade". O "efeito substituição” requer uma sistemática adaptação das linhas da matriz de insumo-produto, porque indica o uso feito pelas diversas indústrias dos insumos provenientes de uma dada indústria. O "efeito produtividade" provoca uma adaptação nas colunas, já que indica a utilização de insumos ocorrida no processo produtivo gerador de certo produto, isto é, qual a contribuição das diversas indústrias para gerar o produto de uma indústria específica (O'CONNOR; HENRY, 1975; TEIXEIRA; SILVA, 1978).

4 Ressalta-se que o método RAS possui algumas limitações, a saber: i) a matriz para o ano-alvo é estimada a partir da utilização da matriz de coeficientes técnicos do ano-base e ii) o algoritmo do método RAS pode não convergir quando os efeitos substituição e produtividade não são atendidos simultaneamente, ou seja, quando as células não atendem simultaneamente às restrições de somas nas linhas e nas colunas (MILLER; BLAIR, 2009). 
O método RAS é conhecido também como método biproporcional. De acordo com a terminologia de Stone, RAS é um código proveniente da notação:

$$
a_{i j}{ }^{*}=r_{i} a_{i j} s_{j} \operatorname{com} i, j=1,2, \ldots, 20
$$

onde $a_{i j}$ e $a_{i j}$ "são, respectivamente, os valores do (i, j)-ésimo coeficiente técnico no período inicial e no período estimado. Os componentes $r_{i}$ e $s_{j}$ são dois tipos de multiplicadores, onde o primeiro indica o efeito substituição e o segundo o efeito produtividade.

Abordando o método do ponto de vista matricial, a operação necessária para obter $A^{*}=\left\{a_{i j}{ }^{*}\right\}$ a partir de $A=\left\{a_{i j}\right\}$ consiste em pré-multiplicar A pela matriz diagonal $\hat{r}$ dos multiplicadores $r_{i}$ e pós-multiplicar pela matriz diagonal $\hat{S}$ dos multiplicadores $s_{j}$, considerando que essas matrizes têm a mesma dimensão $(n X n)$. Com isso, a relação entre a matriz original e a estimada será dada por:

$$
\mathrm{A}^{*}=\hat{r} \mathrm{~A} \hat{S}
$$

Usando a pré-multiplicação, obtêm-se o ajustamento das linhas e, pela pós-multiplicação, o ajustamento das colunas, desde que $\hat{r}$ e $\hat{S}$ sejam conhecidos. Conforme aponta Teixeira e Silva (1978), o problema consiste, então, em encontrar uma matriz $A^{*}$ que reflita a influência sistemática dos efeitos substituição e produtividade sobre as transformações tecnológicas durante o período considerado.

O tipo de informação necessária para aplicar o método RAS, como anteriormente citado, requer a utilização de um vetor $n$-dimensional $x$, valor bruto da produção; do vetor $n$-dimensional $v$, vetor de soma das colunas dos fluxos intermediários (compras) dos $n$ setores produtivos e do vetor $n$-dimensional $y$, representando a demanda final, vetores relacionados ao período que se pretende projetar a matriz de insumo-produto (2009). Usando os dados do ano alvo, é possível calcular o vetor $n$-dimensional $u$, que representa vetor de soma das linhas dos fluxos intermediários (vendas) dos $n$ setores produtivos, e o vetor $n$-dimensional $z$, que indica o consumo intermediário total por meio das expressões:

$$
\begin{aligned}
& u=x-y \\
& z=x-v
\end{aligned}
$$

Formalizando o método descrito, o primeiro passo a ser seguido é usar a hipótese de que A seja igual a $\mathrm{A}^{*}$, ou seja, que os coeficientes técnicos tenham permanecido constantes ao longo do tempo analisado. Diante disso, se $[\mathrm{A} \hat{X}(2009)] \mathrm{i}^{5}$ (soma das linhas do setor i) for igual a $\mathrm{U}^{1}$ e i` $[\mathrm{A} \hat{X}(2009)]$ (soma das colunas do setor i)

$5 \quad$ i é um vetor unitário $20 \times 1$. 
for igual a $\mathrm{V}^{1}$, o ajuste está terminado, mostrando que o coeficiente da matriz do ano base (A) em conjunto com o novo valor bruto da produção gera a nova matriz interindustrial. Todavia, geralmente $U(2009) \neq U^{1}$ e $V(2009) \neq V^{1}$.

Representando $R^{1}$ como a taxa $U(2009) U^{1}$ e sendo $R^{1}$ diferente da unidade, faz-se a pré-multiplicação da matriz $A$ pela matriz diagonal de $R^{1}$ que resultará na matriz $A^{1}$. Fazendo o somatório das colunas de $A^{1}$, encontra-se o vetor $V^{1}$. Definindo $S^{1}$ como a taxa $V(2009) / V^{1}$ e sendo $S^{1}$ diferente da unidade, pós-multiplica-se a matriz $A^{1}$ pela matriz diagonal de $S^{1}$, que resultará na matriz $A^{2}$. Os cálculos supracitados serão feitos de forma iterativa até que $R$ e $S$ convirjam para a unidade. Após a convergência de $R$ e $S$, é feita a pré-multiplicação $R$ por $A$ e a pós-multiplicação de $A$ por $S$. Dessa forma, encontra-se a matriz de coeficientes técnicos para o ano alvo (2009). Em notação matricial, tem-se:

$$
A^{*}=R A S
$$

onde $\mathrm{A}^{*}$ denota a matriz inter-regional de coeficientes técnicos ou diretos do Rio de Janeiro x restante do Brasil para o ano de 2009. Para encontrar os fluxos monetários intermediários para o ano de 2009 (Z(2009)), basta fazer a seguinte multiplicação:

$$
Z(2009)=X(2009) A^{*}
$$

\subsection{Indicadores Básicos de Insumo-Produto: Multiplicador de Produção e Índices de Interligação}

A análise dos multiplicadores setoriais é uma abordagem tradicional derivada das matrizes de insumo-produto. Os multiplicadores complementam a análise da importância de determinado setor na economia, pois permitem avaliar os impactos sobre determinado sistema econômico resultantes de choques exógenos (RODRIGUES et al., 2007). Os multiplicadores mais utilizados são aqueles que estimam os efeitos de uma mudança exógena na demanda final.

\subsubsection{Multiplicador de Produção}

O multiplicador de produção para cada setor é a soma da sua respectiva coluna na matriz inversa de Leontief. Ele corresponde a uma variação direta e indireta da produção total da economia de todos os setores e regiões decorrente da variação exógena de uma unidade monetária da demanda final de determinado setor de uma região (MILLER; BLAIR, 2009). Assim, o multiplicador do produto para o setor $\mathrm{j}$ é definido como o valor total da produção adicional em todos os 
setores da economia que são necessários para satisfazer uma unidade monetária adicional da demanda final do produto do setor $j$. Em termos formais, o multiplicador de produção simples para o setor $j$ da região $R, O_{\_} J^{\wedge} R$, será dado por:

$$
O_{J}^{R}=\sum_{I=1}^{20} b_{i j}
$$

onde:

$R$ representa as regiões Rio de Janeiro e restante do Brasil;

j é um determinado setor da economia;

bij - cada elemento da matriz inversa de Leontief onde $i$ são as linhas e j são as colunas;

$n$ equivale ao número de linhas da matriz.

\subsection{2 Índices de Interligação e Setores-Chave}

A ideia de dependência setorial, linkages setoriais e interdependência regional é tratada pela literatura de insumo-produto de várias formas. Rasmussen (1952) e Hirschman (1958) utilizam os índices de ligação para trás e para frente para estabelecer os setores que teriam o maior poder de encadeamento dentro da economia. Os linkages para trás (poder de dispersão) - $\mathrm{U}_{\mathrm{J}}^{\mathrm{R}}$ - determinam o quanto um setor demanda dos demais setores da economia e os linkages para frente (sensibilidade da dispersão) $-\mathrm{U}_{\mathrm{i}}^{\mathrm{R}}$ - determinam o quanto esse setor é demandado pelos demais setores da economia.

Para o cálculo dos efeitos de encadeamento para trás e para frente, deve-se utilizar a matriz inversa de Leontief. Os índices são formalizados abaixo:

Índice de ligação para trás:

$$
U_{J}^{R}=\frac{b \cdot j / n}{B^{*}}
$$

Onde:

b.j - soma das colunas de $B$;

$b . j$ n é o valor médio dos elementos na linha $i$;

b.. - corresponde à soma total da matriz $B$;

$B^{*}$ - valor médio de todos os elementos de $B$, ou seja, $B^{*}=b . . / n 2$.

Índice de ligação para frente:

$$
U_{i}^{R}=\frac{b i \cdot / n}{B^{*}}
$$


Em que:

bi. - soma das linhas de $B$;

$\mathrm{bi} / \mathrm{n}$ - corresponde ao valor médio dos elementos na coluna j.

O índice de ligação para trás $\left(U_{J}^{R}\right)$ determina o quanto um setor de uma determinada região compra dos demais setores da economia. Se esse índice for superior à unidade, isto significa que, quando há uma variação na demanda final do setor $\mathrm{j}$ da região $\mathrm{R}$, o mesmo gera uma compra de insumos acima da média na economia, revelando fortes encadeamentos para trás no sistema produtivo.

$O$ índice de ligação para frente $\left(U_{i}^{R}\right)$ descreve o quanto o setor $i$ da região $R$ vende para o restante da economia. $\mathrm{Se}_{\mathrm{i}}^{\mathrm{R}}>1$, então, nesse caso, o índice mostra que, diante de uma variação na demanda final de todas as atividades econômicas, a produção do setor $i$ da região $R$ aumenta acima da média na economia. Tal fato aponta que os demais setores da economia possuem uma dependência acima da média da produção do setor $i$ da região $R$, uma vez que o setor $i$ se destaca como forte fornecedor de insumos (encadeamentos para frente) para a economia em geral.

Se um determinado setor apresentar valores de $U_{J}^{R}$ e $U_{i}^{R}$ superiores à unidade, isto significa que o mesmo é considerado setor-chave na economia de uma determinada região, visto que provoca um efeito de encadeamento de compra e venda acima da média.

\subsection{Descrição da base de dados}

Para alcançar o objetivo proposto, este trabalho utiliza a matriz de insumo-produto inter-regional Rio de Janeiro x restante do Brasil para o ano de 2004 com tecnologia setor x setor distribuído em 20 setores para cada região. Essa matriz foi construída por Guilhoto et al. (2010). Visando construir os vetores do valor bruto da produção, da demanda final, do valor adicionado, das vendas e das compras interindustriais para o ano de 2009, foi utilizada como fonte de dados as contas regionais 2010 disponibilizadas pelo Instituto Brasileiro de Geografia e Estatística (IBGE, 2012). Para a construção desses vetores, utilizou-se a estrutura produtiva do ano de 2004 como base para a distribuição dos valores de 2009. Cabe ressaltar que esse procedimento foi realizado de forma individualizada para o Rio de Janeiro e, a posteriori, para o restante do Brasil (GUILHOTO; SESSO FILHO, 2005, 2010). Vale lembrar que os vetores construídos para o ano de 2009 são necessários para a aplicação do método RAS.

Para a construção dos vetores dos "choques", quais sejam vetores de demanda final do ano de 2009 adicionado aos gastos dos megaeventos referentes à Copa do Mundo e às Olimpíadas, foram utilizados os montantes dispendidos 
disponibilizados pelo Portal da Transparência do Brasil e do Rio de Janeiro, ambos sob a responsabilidade da Controladoria-Geral da União (BRASIL, 2014). Com o intuito de construir os vetores dos choques, foi necessária uma compatibilização entre as áreas que se beneficiaram dos investimentos dos megaeventos e os setores da MIP. Essa compatibilização foi feita da seguinte forma: as áreas de construção de acomodações e instalações esportivas, aeroportos, desenvolvimento turístico e estádios e estruturas temporárias foram alocadas no setor de construção da MIP. Já o dispêndio na área de transporte e mobilidade urbana foi alocado no setor de transporte. O setor de Governo e Serviços Públicos recebeu os gastos em segurança e, por fim, o setor de Material Elétrico e Eletrônicos recebeu o dispêndio da área de tecnologia. ${ }^{6}$

Salienta-se ainda que diante da compatibilização supracitada, foram construídos cinco vetores de choque, a saber: i) um vetor de choque total, ou seja, um vetor de demanda final que contempla o gasto total realizado na Copa do Mundo e nas Olimpíadas; ii) um vetor de demanda final de 2009 adicionando os gastos totais no setor de Construção do Rio de Janeiro; iii) um vetor de demanda final de 2009 adicionando os gastos totais no setor de Material Elétrico e Eletrônicos do Rio de Janeiro; iv) um vetor de demanda final de 2009 adicionando os gastos totais no setor de Transportes do Rio de Janeiro e, finalmente, v) um vetor de demanda final de 2009 adicionando os gastos totais no setor de Governo e Serviços Públicos do Rio de Janeiro.

\section{Resultados e Discussão}

Nesta seção, são analisados alguns indicadores da análise de insumo-produto baseados nas ligações diretas, indiretas e induzidas das atividades produtivas intra e inter-regionais derivados da matriz inversa de Leontief, atualizada para o ano de 2009. Esses indicadores visam uma avaliação preliminar da MIP Rio de Janeiro x restante do Brasil. Ademais, baseada na MIP atualizada para 2009, serão descritos os resultados provenientes dos impactos dos investimentos decorrentes dos megaeventos sediados pelo Estado do Rio de Janeiro.

Sob uma perspectiva intra-regional, a interdependência setorial de uma economia pode ser avaliada por meio de índices que sintetizam as interligações, a montante e a jusante das atividades produtivas como, a exemplo, os índices desenvolvidos por Rasmussen (1956) e Hirschman (1958). Os resultados desses índices de interligação, para cada setor da MIP Rio de Janeiro x restante do Brasil estão reportados na Tabela 1 (colunas 3 a 5). Embora diversos setores apresentem índices superiores à unidade nas duas regiões, observa-se a existência de dois setores-

6 A compatibilização encontra-se no Apêndice 1, enquanto os montantes despendidos podem ser encontrados no Portal da Transparência (BRASIL, 2014). 
-chave no Rio de Janeiro (Mineração e Energia Elétrica). No que se refere à Mineração, esse achado pode ser justificado pelo fato de a economia fluminense, no ano de 2009, ter sido a maior prospectora de petróleo com produção de 96.221 milhões de m3, representando 85\% da produção nacional (RIO DE JANEIRO, 2011). Quanto ao setor de Energia Elétrica, o parque gerador elétrico fluminense, composto por usinas hidrelétricas, térmicas convencionais e termonucleares, atingiu uma capacidade instalada superior a 7,4 GW em 2009. Nesse mesmo ano, a produção de eletricidade do estado do Rio de Janeiro foi de $34.152 \mathrm{GWh}$, que representou 7,3\% da produção nacional, e o consumo de $38.944 \mathrm{GWh}$ representou 9,1\% do consumo do país (RIO DE JANEIRO, 2011). Convém discorrer, ainda, que o Rio de Janeiro trata-se de um estado de economia mais desenvolvida, com estrutura produtiva fortemente especializada em serviços terciários e quaternários (HADDAD et al., 2008), serviços altamente demandantes de insumos energéticos. Portanto, era esperado que o setor de Energia Elétrica fosse considerado um setor-chave para a economia fluminense.

Resultado que também merece destaque é o fato de que nove dos vinte setores do Rio de Janeiro analisados por este estudo possuem poder de dispersão acima da média, o que revela características regionais interessantes, isto é, esses setores possuem a característica de induzir a atividade produtiva intra-regional. No caso do restante do Brasil, sete setores apresentaram-se como setores-chave no ano de 2009, quais sejam: Metalurgia, Material Elétrico e Eletrônicos, Madeira, Mobiliário, Papel, Refino de Petróleo e Coque, Outros Químicos e Farmacêuticos, Têxtil, Vestuário, Calçados e Produtos Alimentícios.

Conforme apontado por Palermo et al. (2010), embora os índices de interligações de Rasmussen-Hirschman permitam diagnosticar algumas diferenças estruturais entre as regiões, o mecanismo subjacente é puramente intra-regional na medida em que não se considera o papel das relações de comércio inter-regional na composição do consumo intermediário de cada região. Em virtude do assinalado pelos autores, os multiplicadores de produção e sua respectiva decomposição dos efeitos regionais foram calculados para a matriz de insumo-produto inter-regional Rio de Janeiro x restante do Brasil como forma de avaliar o papel das transações inter-regionais. Por meio de uma inspeção visual das colunas 6, 7 e 8 da Tabela 1, nota-se que, em média, a participação intra-regional no Rio de Janeiro é menor do que aquela no restante do Brasil. Resultado esperado, haja vista que a economia do Rio de Janeiro é menor, em termos dimensionais, ao restante do Brasil, o que ocasiona maiores níveis de transbordamento.

Analisando os multiplicadores de produção de forma pormenorizada, nota-se que o impacto médio de uma unidade monetária adicional na demanda final do Rio de Janeiro aumenta a produção intra-regional em 2,09 unidades monetárias. Ainda com base na análise dos multiplicadores, é possível verificar que varia- 
ções na demanda final do Rio de Janeiro impulsionam a produção intra-regional em $73,7 \%$, enquanto que a produção inter-regional é estimulada em $26,3 \%$, o que pode ser devido ao fato de que o Rio de Janeiro possui muitos setores com poder de dispersão acima da média. Os cinco setores com maior multiplicador de produção no ano de 2009 para o Rio de Janeiro foram: Material de Transporte, Refino de Petróleo e Coque, Produtos Alimentícios, Outros Químicos e Farmacêuticos e Máquinas e Equipamentos. Por outro lado, os setores que apresentaram os menores multiplicadores de produção foram os seguintes: Comércio, Governo e Serviços Públicos, Serviços Privados, Agropecuária e Construção.

No que se refere à análise do multiplicador de produção do restante do Brasil, nota-se que sua parcela intra-regional sempre supera a parcela inter-regional, demonstrando que variações na demanda final do restante do Brasil não geram efeito transbordamento expressivo sobre a economia fluminense, uma vez que 95,6\% da variação na demanda final ocorrida no restante do Brasil permanece nesta região. Padrão semelhante fora observado para a economia do Rio de Janeiro. 


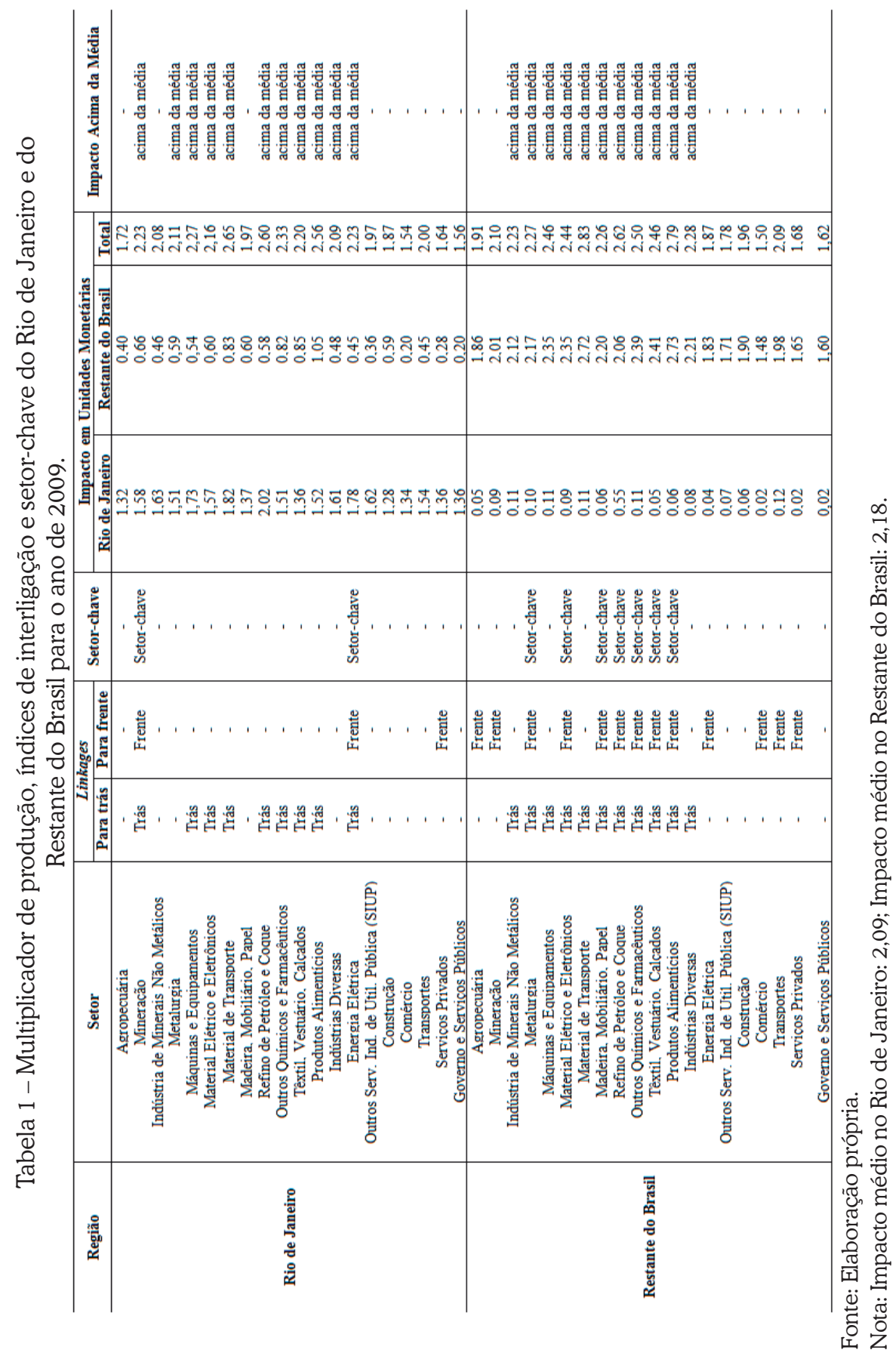

CABRAL, J. A.; CABRAL, M. V. F.; SILVA, T. M. K. Impactos Econômicos Regionais... 
Muito se tem especulado sobre os efeitos econômicos dos investimentos decorrentes dos megaeventos sediados pelo Rio de Janeiro. Visando contribuir com a discussão, o presente estudo realizou uma análise desses impactos na cadeia produtiva intra e inter-regional por meio da análise inter-regional de insumo-produto. Esses resultados podem ser observados por meio da análise da Tabela 2. Em linhas gerais, em relação ao PIB de 2009, o PIB do Rio de Janeiro cresceu 13\% em virtude desses investimentos, enquanto o PIB do restante do Brasil aumentou somente $0,45 \%$. Esse resultado mostra-se interessante, pois conforme observado anteriormente, por meio da análise dos índices de interligação e do multiplicador de produção, o Rio de Janeiro possui forte encadeamento intra-regional. O baixo impacto sobre o valor adicionado do restante do Brasil não é surpreendente devido às baixas taxas de crescimento econômico experimentadas nos últimos anos pela economia brasileira.

Analisando detalhadamente a Tabela 2, é possível verificar os choques individualizados constantes nas colunas de 3 a 6 . Posto de outra forma, essas colunas apresentam a variação percentual do valor adicionado intra e inter-setorial, em relação ao ano de 2009, oriunda da variação na demanda final dos setores que foram contemplados com os investimentos decorrentes dos megaeventos esportivos. Relativo ao choque no setor de Construção (coluna 3), os cinco setores que mais se beneficiaram foram: o próprio setor de Construção (76,4\%), Indústria de Minerais não Metálicos (15,4\%), Metalurgia (3,8\%) e Comércio (2,9\%), todos do Rio de Janeiro, e Indústria de Minerais não Metálicos (8,5\%) do restante do Brasil. Esse resultado possui aderência, uma vez que os setores mais beneficiados com o aumento na demanda final do setor de Construção são, de fato, os que possuem maior encadeamento com o referido setor.

Em relação ao choque no setor de Transporte (coluna 4), os setores que mais se beneficiaram com o aumento da demanda final desse setor foram: o próprio setor de Transporte (109,2\%), Refino de Petróleo e Coque (11,8\%), Comércio (4,6\%), SIUP (4\%) e Energia Elétrica (3,4\%). Salienta-se que nenhum setor da região do restante do Brasil figurou entre os cinco setores mais beneficiados. Os setores que obtiveram considerável variação percentual no valor adicionado resultante do choque no setor de Material Elétrico e Eletrônicos (coluna 5) foram o próprio setor (17,4\%) e a Indústria de Minerais não Metálicos do restante do Brasil (2,4\%). Os demais setores apresentaram crescimento abaixo de $0,5 \%$, evidenciando que o setor de Material Elétrico e Eletrônicos, considerado como setor de alta intensidade tecnológica (FURTADO; CARVALHO, 2005), possui baixo dinamismo diante das estruturas produtivas do Rio de Janeiro e do restante do Brasil, compostas, basicamente, de setores de baixa e média tecnologia. No que tange ao choque no setor de Governo e Serviços Públicos (coluna 6), pelo fato de possuir baixos en- 
cadeamentos intra e inter-setoriais, não apresentou variação significativa no valor adicionado.

Os impactos derivados dos investimentos dos megaeventos propriamente ditos podem ser averiguados na coluna 7 da Tabela 2. Conforme pode ser observado, os cinco setores mais favorecidos pela realização dos megaeventos esportivos foram: Transporte (111\%), Construção (76,7\%), Material Elétrico e Eletrônicos (18,1\%), Indústria de Minerais não Metálicos (15,8\%) e Refino de Petróleo e Coque $(13,4 \%)$. O setor de Transporte do Rio de Janeiro mostrou-se o mais beneficiado com a realização dos megaeventos. Isso pode ser devido ao fato de que foi o setor que recebeu mais da metade dos recursos destinados à Copa do Mundo e às Olimpíadas (51,8\%). Esse investimento foi necessário, tendo em vista que o setor de Transporte do Rio de Janeiro é um gargalo na economia fluminense e, por outro lado, é de suma importância para a fluidez e operacionalização da mobilidade urbana que ocorrem durante eventos desse porte.

O setor de Construção, segundo maior beneficiário com os investimentos advindos da realização dos megaeventos, foi consideravelmente impactado, tendo em vista algumas ações que fazem parte do dossiê de candidatura do Rio de Janeiro como cidade-sede da Copa do Mundo e das Olimpíadas, a saber: a reforma do Maracanã, a construção do corredor viário T5, a recuperação e revitalização do Aeroporto Internacional Antônio Carlos Jobim (Galeão) e investimento em estruturas temporárias, além de construção de instalações esportivas para atender, especificamente, os Jogos Olímpicos.

Uma possível explicação para o terceiro lugar ocupado pelo setor de Material Elétrico e Eletrônicos é o fato de que o setor é insumo para a infraestrutura de telecomunicação necessária durante os megaeventos (transmissão dos jogos, por exemplo). A quarta e quinta colocações são destinadas, respectivamente, aos setores de Indústria de Minerais não Metálicos e Refino de Petróleo e Coque, insumos básicos para os dois setores mais beneficiados com os recursos dispendidos para a realização dos megaeventos esportivos no Rio de Janeiro. 


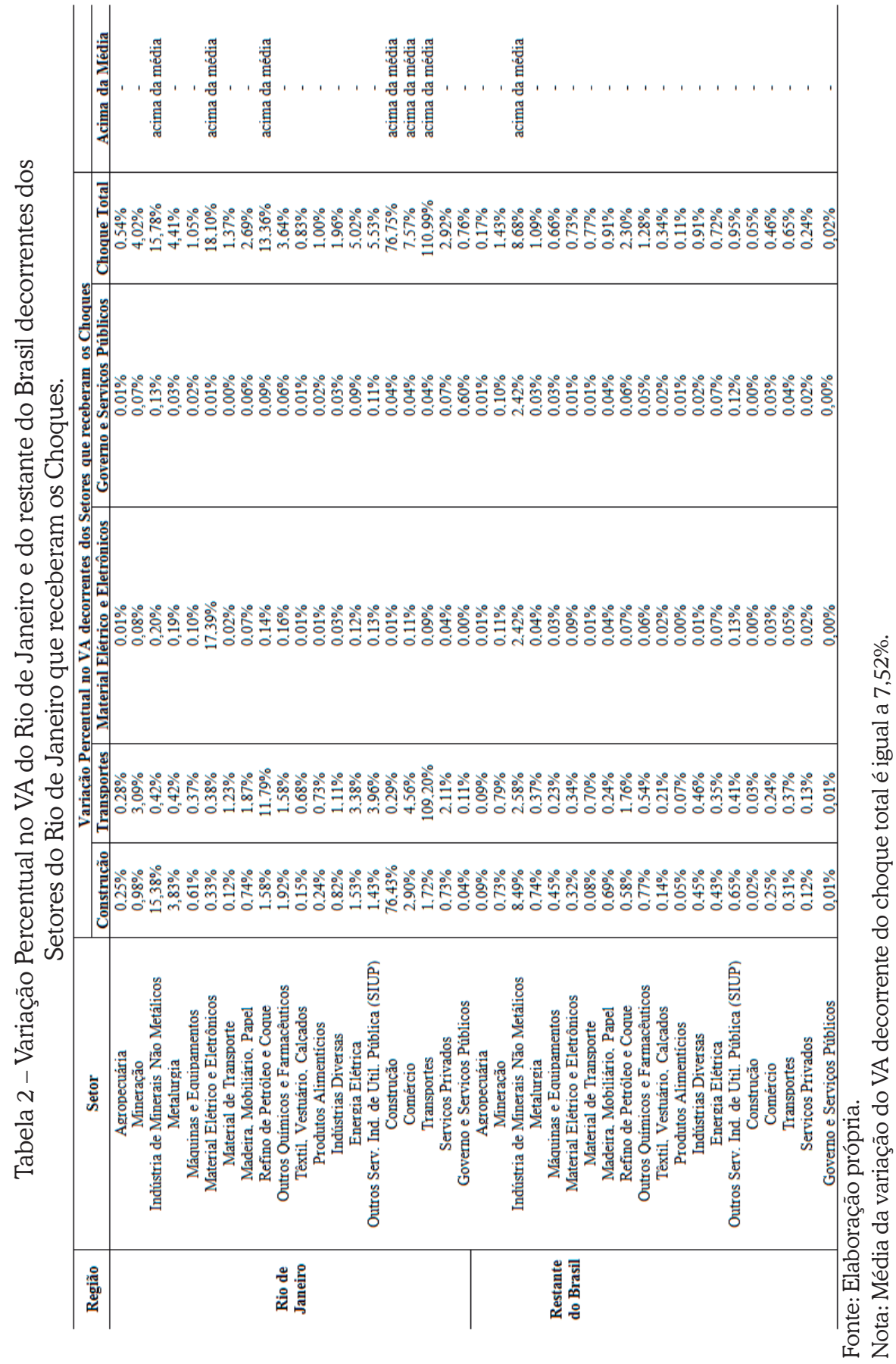


Convém observar ainda que há coincidência entre o dinamismo do PIB setorial e a contemplação de montante dispendido para a preparação dos megaeventos dos três primeiros setores do Rio de Janeiro, isto é, os setores do Rio de Janeiro que receberam maior nível de recursos oriundos da realização dos megaeventos são justamente os que obtiveram os maiores impactos sobre os seus respectivos valores adicionados. Uma ressalva deve ser feita, afinal esses setores não possuem fortes encadeamentos intra e inter-setoriais e, por conseguinte, o crescimento proveniente dos megaeventos não será sustentado ao longo do tempo, uma vez que os setores não possuem o poder de dinamizar a economia fluminense por não serem setores-chave na economia do Rio de Janeiro.

\section{Considerações Finais}

Tendo em vista o panorama de retomada de investimentos por ocasião dos megaeventos esportivos a serem realizados no país, fez-se necessário o entendimento do comportamento dos fluxos de recursos sobre a cadeia produtiva da economia fluminense para a dinâmica de desenvolvimento do estado do Rio de Janeiro e para o restante do Brasil, de modo a investigar se esses investimentos surtirão os efeitos esperados pelo Ministério do Esporte sobre as economias fluminense e do restante do Brasil. Nesse contexto, o objetivo central do presente trabalho foi mensurar os impactos regionais oriundos dos investimentos da Copa do Mundo de 2014 e dos Jogos Olímpicos de 2016 para a economia do estado do Rio de Janeiro e os possíveis transbordamentos desses investimentos para outras regiões do Brasil. Para tal, foi utilizada a matriz de insumo-produto (MIP) inter-regional Rio de Janeiro x restante do Brasil do ano de 2004, disposta em 20 setores produtivos para cada região como base para a atualização da MIP de 2004 para o ano de 2009, por meio do método RAS, de modo a implementar o modelo inter-regional de insumo-produto e seus indicadores clássicos.

A análise dos resultados para a matriz de insumo-produto inter-regional Rio de Janeiro x restante do Brasil, através de índices de ligações Rasmussen-Hirschman, revelou que os setores-chave da economia do Rio de Janeiro são Mineração e Energia Elétrica, afinal, trata-se do maior estado prospector de petróleo no Brasil e com considerável parque gerador elétrico. Quanto ao multiplicador de produção, a parcela intra-regional sempre supera a parcela inter-regional, demonstrando que variações na demanda final do Rio de Janeiro não geram efeito transbordamento expressivo sobre a economia do restante do Brasil e vice-versa. Resultado interessante foi o crescimento do PIB, em virtude dos investimentos advindos da realização dos megaeventos, em 13\% para o Rio de Janeiro e somente 0,45\% para o restante do Brasil, relativamente ao PIB de 2009. Entretanto, o crescimento da economia fluminense não será sustentado, uma vez que os setores de Transporte, 
Construção e Material Elétrico e Eletrônicos do Rio de Janeiro, que obtiveram maior impacto sobre o valor adicionado, não possuem o poder de dinamizar sua economia por não possuírem fortes encadeamentos intra e inter-setoriais.

Como agenda de pesquisa, pretende-se avançar na investigação dos impactos advindos com a realização dos megaeventos sobre a geração de emprego no Rio de Janeiro. Além disso, propõe-se investigar o impacto dos gastos turísticos durante os megaeventos no Rio de Janeiro.

\section{Referências}

BETARELLI JUNIOR, A. A. Análise dos modais de transporte pela ótica dos blocos comerciais: uma abordagem inter-setorial de insumo-produto. 2007. 173 f. Dissertação (Mestrado em Economia Aplicada) - Faculdade de Economia e Administração, Universidade Federal de Juiz de Fora, Juiz de Fora, 2007.

BONASSA, A.; FARIA, P. Os jogos olímpicos do Brasil. Portal Central de Cases ESPM. 2011. Disponível em: < http://www.espm.br/Publicacoes/CentralDeCases/Documents/ JOGOSOLIMPICOSDOBRASIL.pdf>. Acesso em: 21 ago. 2013.

BRASIL. Controladoria Geral da União. Portal da Transparência. Copa 2014. Rio de Janeiro. Disponível em: <http://www.portaltransparencia.gov.br/copa2014/cidades/home. seam?cidadeSede $=10>$. Acesso em: 15 jan. 2014.

. Controladoria Geral da União. Portal da Transparência. Jogos Rio 2016. Quadro Resumo. Disponível em: <http://www.portaltransparencia.gov.br/rio2016/matriz>. Acesso em: 15 jan. 2014.

- Ministério do Esporte Janeiro. Matriz de responsabilidades da Unidade Federativas. 2010. Disponível em: <http://www.esporte.gov.br/assessoriaEspecialFutebol/ compromissosCopa2014.jsp>. Acesso em: 03 nov. 2013.

CABRAL, J. A.; PEROBELLI, F. S. Análise de decomposição estrutural para o setor de saúde brasileiro - 2000-2005. Pesquisa e Planejamento Econômico, v. 42, n. 3, p. 363-402, 2012.

COSTA, G. Sediar megaeventos esportivos vale à pena? O Social em Questão, ano 16, n. 29, p.159-178, 2013.

DOMINGUES, E. P.; BETARELLI JUNIOR, A. A.; MAGALHAES, A. S. Quanto vale o show? Impactos econômicos dos investimentos da Copa do Mundo 2014 no Brasil. Estudos Econômicos, v. 41, n. 2, p. 409-439, 2011.

FURTADO, A. T.; CARVALHO, R. Q. Padrões de intensidade tecnológica da indústria brasileira: um estudo comparativo com os países centrais. São Paulo em Perspectiva, v. 19, n. 1, p. 70-84, 2005.

GANGULY, N. P. Economic impact and investing opportunities of the two upcoming mega events in Brazil - 2014 FIFA World Cup and 2016 Olympic Games. CRISIL Young Thought Leader, 2012. Disponível em: < http://crisil.com/crisil-young-thought-leader-2012/ dissertations/9-nrsingha-ganguly.pdf > . Acesso em: 13 ago. 2013. 
GUILHOTO, J. J. M. et al. Matriz de insumo-produto do nordeste e estados: metodologia e resultados. Fortaleza: Banco do Nordeste do Brasil, 289 p. 2010.

GUILHOTO, J. J. M.; SESSO FILHO, U. A. Estimação da matriz insumo-produto a partir de dados preliminares das contas nacionais. Economia Aplicada, v. 9, n. 2, p. 277-299. abr./jun. 2005.

Estimação da matriz insumo-produto utilizando dados preliminares das contas nacionais: aplicação e análise de indicadores econômicos para o Brasil em 2005. Economia E Tecnologia. ano 6, v. 23, p. 53-62, 2010.

HADDAD, E. A. et al. Impactos socioeconômicos dos jogos pan-americanos (atualização). Relatório Final. São Paulo: Fipe, nov. 2008.

HIRSCHMAN, A. O. The strategy of economic development. New Haven: Yale University Press, 1958.

IBGE. Contas regionais do Brasil 2010. Disponível em: <ftp://ftp.ibge.gov.br/Contas Regionais/2010/contasregionais2010.pdf>. Acesso em: 13 jul. 2012.

LAHR, M. L.; DE MESNARD, L. Biproportional techniques in input-output analysis: table updating and structural analysis. Economic Systems Research, v. 16, n. 2, p. 115-134, 2004.

LEONTIEF, W. The structure of American economy, 1919-1929. Cambridge: Harvard University Press, 1941.

LO BIANCO, V. L. O. O legado dos megaeventos esportivos em questão: as mudanças ou as continuidades na cidade Rio de Janeiro pós-sede. 2010. 125 f. Dissertação (Mestrado em Políticas Públicas) - Instituto de Economia, Universidade Federal do Rio de Janeiro, Rio de Janeiro, 2010.

MATHESON, V. A. Mega-events: the effect of the world's biggest sporting events on local, regional, and national economies, Massachusetts: Department of Economics, 2006. (Holy Cross Working Paper Series, n. 06-10).

MILLER, R. E.; BLAIR, P. D. Input-output analysis: foundations and extensions. 2. ed. New York: Cambridge University Press, 2009.

O'CONNOR, R., HENRY, E.W. Input-output analysis and its applications. New York: MacMillan, 1975.

PALERMO, P. U; PORSSE, A. A; PEIXOTO, F. C. Relações setoriais e interdependência regional da economia gaúcha: análise com um modelo inter-regional de insumo-produto. Ensaios FEE, v. 31, n. 1, p. 113-147, 2010.

PERROUX, F. O conceito de pólo de desenvolvimento. In: Schwartzman, J. (Org.) Economia regional: textos escolhidos. Belo Horizonte: Cedeplar, 1977.

PORTO, L. P.; CERON, L. F.; ARAÚJO, L. E. B. Brasil. Copa do Mundo de 2014: análise dos impactos ambientais, econômicos e sociais. Revista Eletrônica do Curso de Direito da UFSM, v. 8, edição especial: I Congresso Internacional de Direito Ambiental e Ecologia Política, p. 437-446, 2013. 
PRONI, M. W. Observações sobre os impactos econômicos esperados dos Jogos Olímpicos de 2016. Motrivivência, ano 21, n. 32/33, p. 49-70, jun./dez. 2009.

PRONI, M. W.; SILVA, L. O. Impactos econômicos da Copa do Mundo de 2014: projeções superestimadas. Campinas: Unicamp, out. 2012. (Texto para Discussão, n. 211). Disponível em: <http://www.eco.unicamp.br/index.php/textos>. Acesso em: 13 ago. 2013.

RASMUSSEN, P. Studies in intersectorial relations. Amsterdam: North Holland, 1956.

RIO DE JANEIRO. Secretaria de Estado de Desenvolvimento Econômico, Energia, Indústria e Serviços. Balanço Energético do Estado do Rio de Janeiro 2009. Rio de Janeiro, 2011.

RODRIGUES, R. L. et al. Transformações na estrutura produtiva da economia paranaense nos anos 80 e 90. Revista de Economia Aplicada, v. 11, n. 1, p. 73-93, 2007.

ROMERO, R. D.; RIBEIRO, P. C. M. Análise de impactos relacionados à mega-eventos e seus custos para o Brasil. In: Rio de Transportes, 7., 2009, Rio de Janeiro. Anais... Rio de Janeiro: COPPE, 2009.

SANTOS NETO, S. C.; GUEDES, C.; SOUZA, M. A. O desenvolvimento local através dos megaeventos esportivos: Rio 2016. In: CONGRESSO DO INSTITUTO FRANCOBRASILEIRO DE ADMINISTRAÇÃO DE EMPRESAS IFBAE, 6., 2011, Franca, SP. Anais... São Paulo: IFBAE, 2011. p. 485-500.

SILVA, C. A. F. et al. Expectativas da mídia sobre o legado das Olimpíadas de 2016: racionalidade instrumental e substantiva. Revista Brasileira de Ciências do Esporte, Florianópolis, v. 33, n. 4, p. 939-957, out./dez. 2011.

SOUZA, R. M.; PEROBELLI, F. S. Mudanças estruturais da economia mineira e do restante do Brasil: uma análise de insumo-produto para o período 1996-2003. Nova Economia, v. 19, n. 3, p. 407-441, 2009.

STONE, R. (Ed.). Input-output relationships, 1954-1966. London: Chapman and Hall, 1963.

TAVARES, O. Quem são os vencedores e os perdedores dos jogos olímpicos? Pensar a Prática, v. 8, n.1, p. 69-84, 2005.

TEIXEIRA, J.; SILVA, D. Modernização da matriz de input-output utilizando modelos matemáticos. Revista Brasileira de Economia, v. 32, n. 1, p. 141-160, 1978. 


\section{Apêndice A}

Tabela 3 - Compatibilização entre as áreas que foram contempladas com os megaeventos esportivos e os setores da MIP

\begin{tabular}{c|c|c}
\hline Área & Setor MIP & $\begin{array}{c}\text { Valor total } \\
\text { (R\$ milhões) }\end{array}$ \\
\hline $\begin{array}{c}\text { Aeroportos } \\
\text { Estádios }\end{array}$ & \\
$\begin{array}{c}\text { Estruturas Temporárias } \\
\text { Instalações Esportivas } \\
\text { Mobilidade Urbana } \\
\text { Transportes } \\
\text { Tecnologia } \\
\text { Segurança }\end{array}$ & Construção $\$ 23.377,62$ \\
\cline { 2 - 3 } & & \\
\cline { 2 - 3 } & Material Elétrico e Eletrônicos & $\mathrm{R} \$ 26.126,00$ \\
\cline { 2 - 3 } & Governo e Serviços Públicos & $\mathrm{R} \$ 477,49,90$ \\
\hline
\end{tabular}

Recebido em: 10/01/2015. Aceito em: 29/10/2015. 